\title{
The secret life of the adder (Vipera berus) revealed through telemetry
}

\author{
N. Hand \\ Central Ecology, 45 Albert Road, Ledbury HR8 2DN \\ E-mail: nigel@centralecology.co.uk
}

\section{INTRODUCTION}

I have radio-tracked the movements of European adder (Vipera berus) populations on six sites in central and southern England since 2010, using telemetry of tagged snakes (Fig. 1A). During eight years of tracking projects, 75 snakes have been successfully fitted with external tags and their movements mapped.

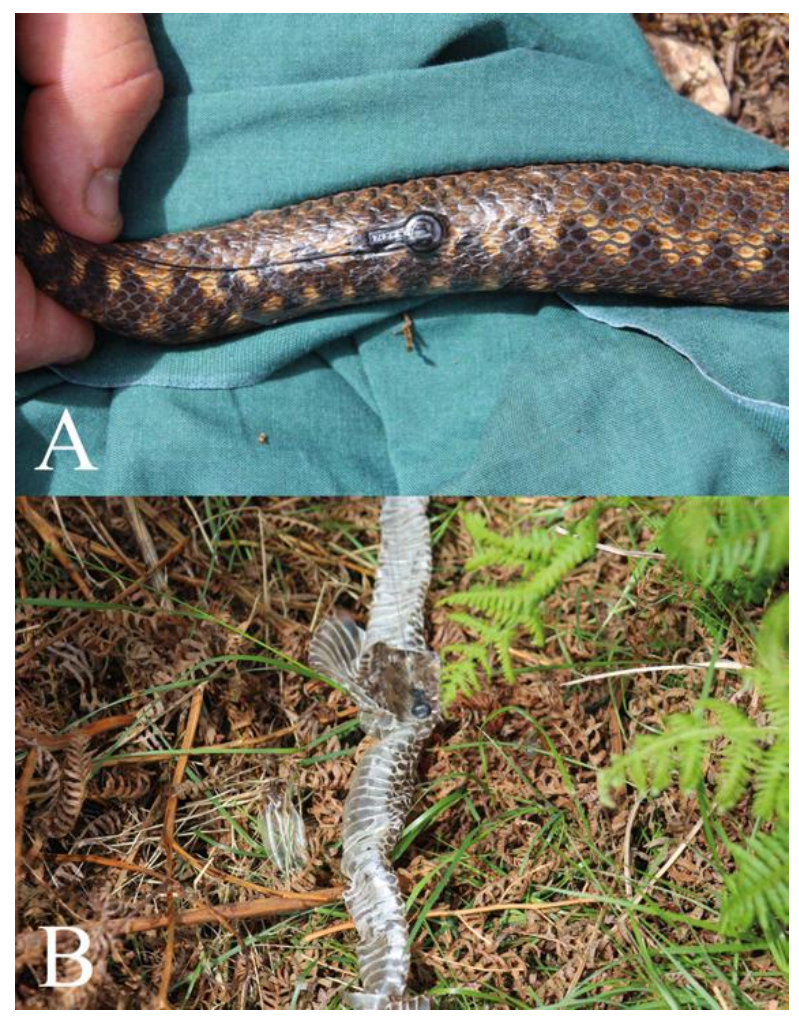

Fig. 1. Telemetry tags used to monitor the movements of adders (Vipera berus). Position of a tag on an adult female (A). Tags are fitted with surgical tape low down the body, avoiding the widest body area. The tape does not go entirely around the body but only a small section applied to the flank. Tags are typically sloughed off on cast skin and retrieved whilst still transmitting (B). (Photos: N. Hand)

The advantages of telemetry are:

1. Snakes have their own tag signal pinpointing the movements of individuals.

2. The movements of snakes are tracked and mapped revealing home ranges.

3. The method allows locating adders which are hidden from view or underground.
4. The data inform landscape management beneficial to snakes.

\section{RESULTS}

I first tested whether externally attached telemetry tags would affect snake behaviour. In 2010 a tag was tested on an adult male for 15 days and activity monitored. In this time the adder was observed basking and moving as expected, with the tag not impeding progress. Tagged snakes have subsequently been recorded in combat, courtship, copulation, basking, and exhibiting evidence of prey ingestion (Fig. 2).

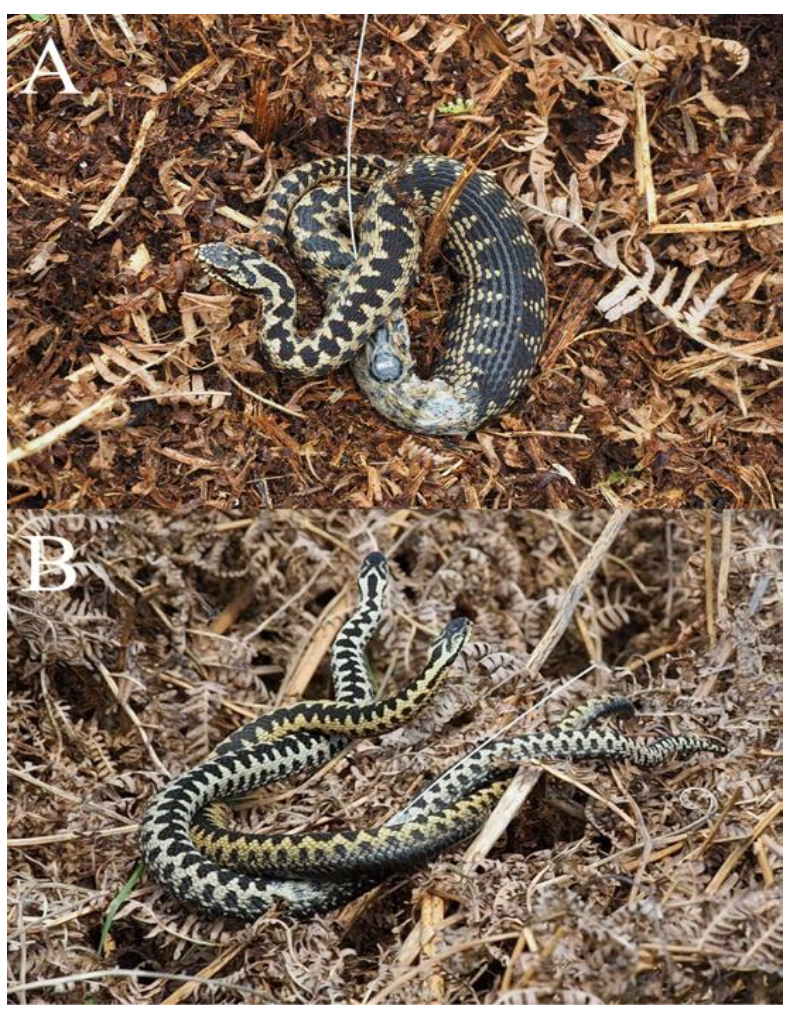

Fig. 2. Adder (Vipera berus) behaviour was unaffected by telemetry tags. A number of tagged snakes have been observed having caught and ingested prey items (A). Tagged snakes have been observed in combat (B), courtship, and mating. (Photos: N. Hand and N. Saunders)

Tags are shed during normal skin sloughing (Fig. 1B), and so tag attachment has to be timed to fit between repeated sloughing cycles. In the Midlands and southern England male adders first slough around 
the second to third week of April, followed by the next slough at the end of May and early June. Most females instead slough for the first time later at the end of May or early June. There are further sloughs for both sexes between July and September, with up to four sloughs per year for an adult adder.

The capture and tag fitting sites were usually close to hibernation sites (hibernacula). Males were also captured searching for mates. Telemetry tags have had a lifespan of 80-90 days, but their project tracking time may be reduced by being cast off during sloughing cycles. The longest continuous tracking of a snake was 101 days, with the tag reapplied to the same snake after sloughing, but the average time was 49 days. The main tracking period is from April to June, covering a mix of breeding and non-breeding adult animals. Tags were not placed on snakes below $35 \mathrm{~cm}$ in length as there is a risk that the tag could impede a snake below this size, so very few juveniles have been monitored.

Fossorial behaviour was evident with all tracked adders. After breeding in mid-May, males became less conspicuous, but were tracked sheltering beneath bracken humus (Pteridium spp.), and below ground in rodent burrows (Fig. 3). Non-breeding females and juveniles also followed this pattern, but gravid females tended to remain above ground basking. Often snakes below ground were found with prey bulges indicating that they were feeding (Fig. 2A). Many snakes appeared to retreat into humid areas when going through the sloughing cycle during late May.
Males were observed mate searching, and with radio telemetry their interactions with other snakes monitored (Figs. 4,5). Males were mapped travelling to breeding sites, with some arrivals leading to other males suddenly deserting breeding areas. In contrast, females were mapped remaining close to capture sites or near to hibernacula. Females traveled on average $158 \mathrm{~m}$ from site of capture to the June skin shed tag location, whereas average male movements were $570 \mathrm{~m}$ from site of capture to shed tag location.

When mapping adder movements through habitats, telemetry revealed vegetation and topography that allowed movements, along with barriers (Figs. 4, 5). It is noteworthy how far males searched for mates, and the variety of habitats that they passed through. Males moved through woodland in April and May when the canopy growth was sparse, and sunlight could reach the ground. They also moved along ride edges during this period. Tracking revealed that power cable wayleave corridors are used as adder routes. Similarly, unmade roads and open mown areas up to $30 \mathrm{~m}$ in width were crossed to reach females or further habitat. Mapping revealed adders could move through mature deciduous woodland. However, adders were not encountered in heavily grazed or short grassland. Movements could be tracked up to the habitat boundary edge, fence line or open area, with snakes then turning back or remaining at the edge.

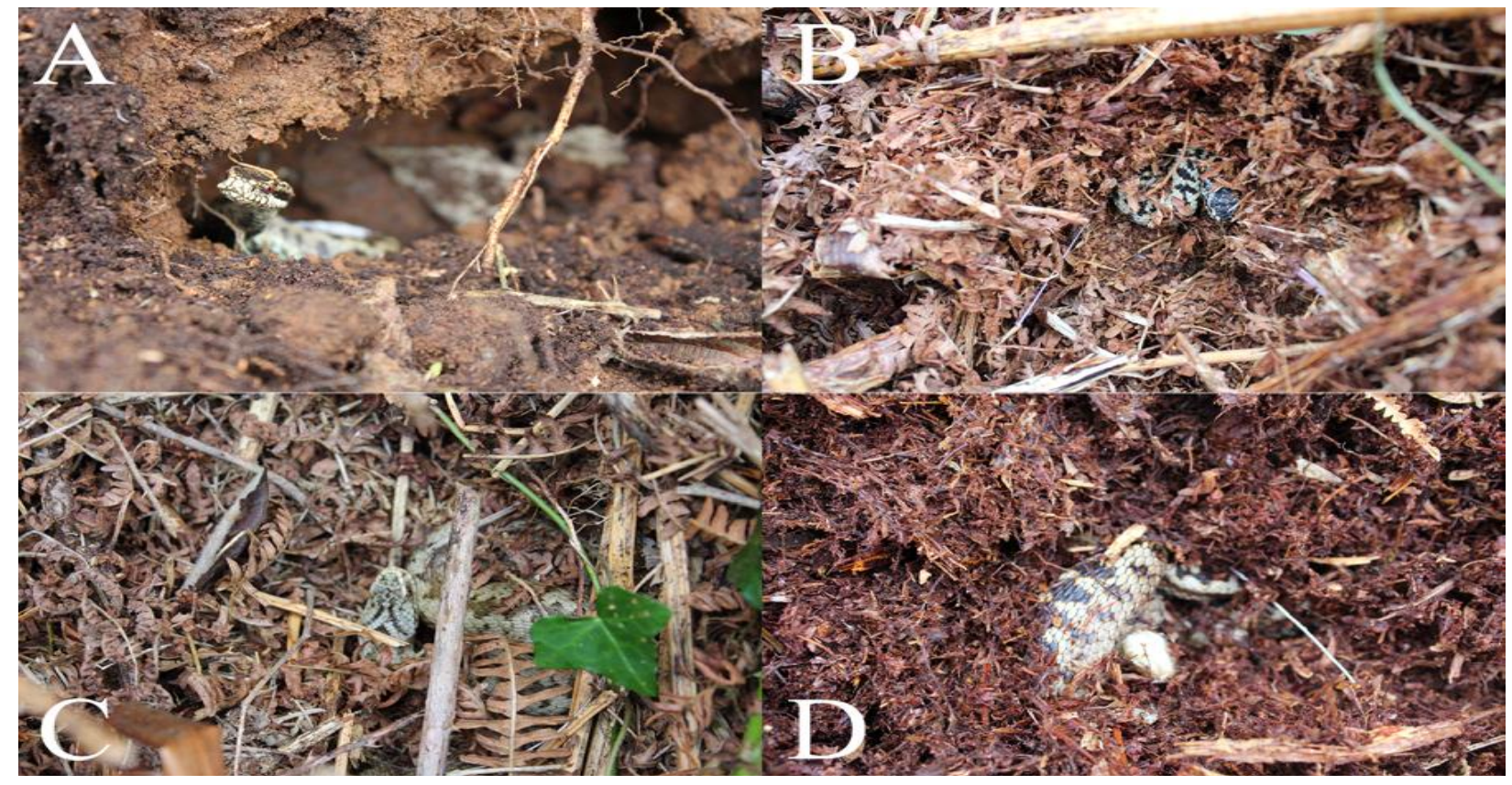

Fig. 3. Tagged adders (Vipera berus) as found in habitat. Males and females spend long periods underneath vegetation (B-D), or in rodent runs and burrows (A). This was either to avoid inclement weather, for hunting prey, or as overnight refuge areas. The images show snakes in habitats dominated by bracken (Pteridium spp.) where they hide underneath bracken thatch. At other sites adders were found underneath gorse (Ulex spp.) needle humus, heather (Calluna vulgaris) roots or moss layers. There are important implications for habitat management due to this behaviour: heavy machinery cutting and collecting could result in snakes being entombed and crushed underground. (Photos: N. Hand) 

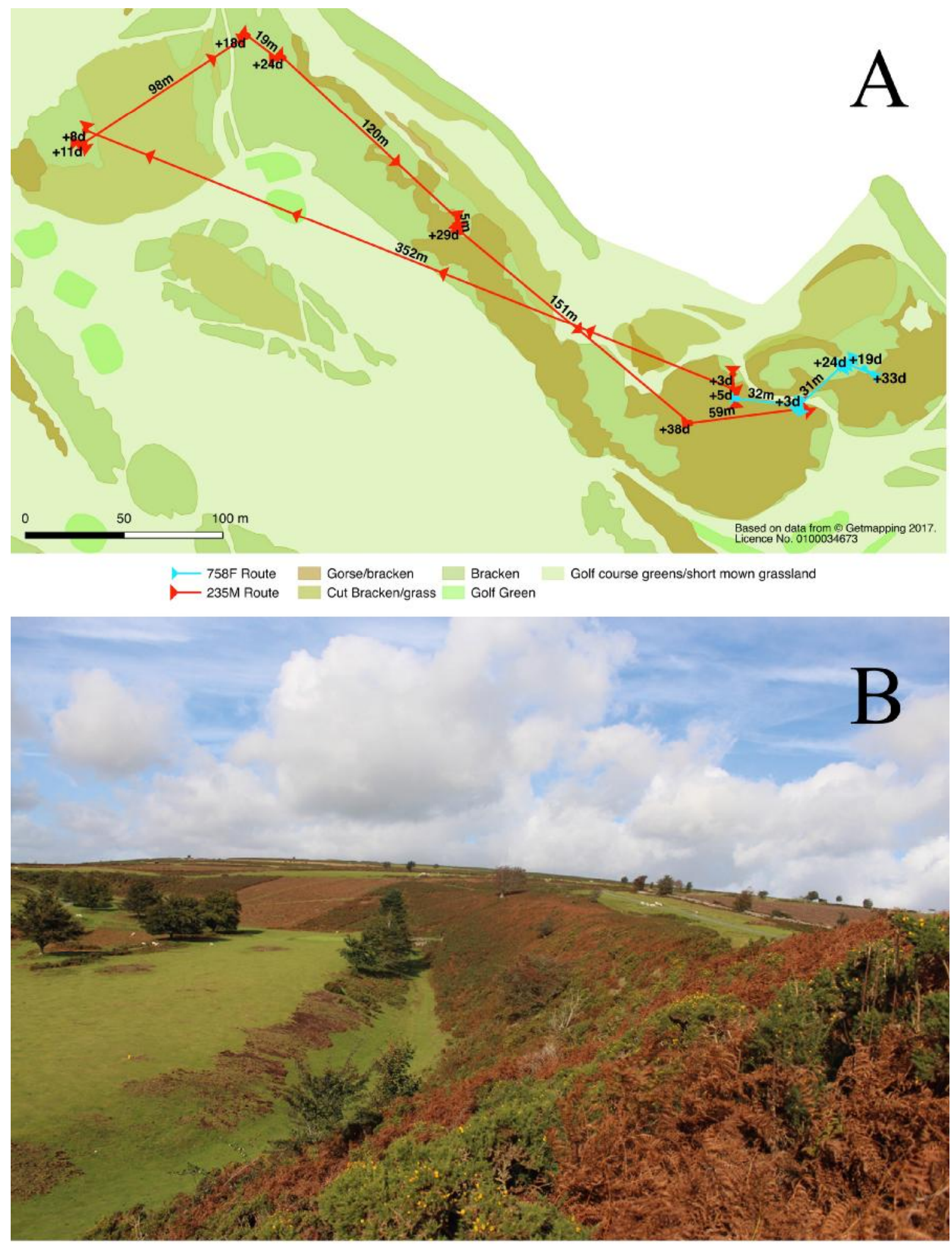

Fig. 4. Adder (Vipera berus) movements of two tracked snakes at a Herefordshire golf course and common, from April to early June 2017. A map (A) and photograph (B) of the study site. Snakes were tracked every two days with their position plotted using a GPS device. The routes of the male 235M (red line) and the female 758F (blue line) are shown. Male 235M tracked for 47 days, used a gorse (Ulex spp.) and bracken (Pteridium spp.) bank during the mate-searching period from April to early June, and was not recorded on short mown golf course fairways or greens. This snake found two females around day eight and day $11(+8 \mathrm{~d},+11 \mathrm{~d})$ and on the return journey crossed a cut bracken/grassland area approximately $30 \mathrm{~m}$ wide, and is suspected to have attempted crossing this area twice. This snake moved $350 \mathrm{~m}$ over $+5 \mathrm{~d}$ to $+8 \mathrm{~d}$, this outward move over three days to lo cate females was between tracking visits. This snake was not seen on the mown greens during tracking and likely travelled within cover. Notably the recorded return back to the initial overwintering area revealed a route through bankside cover. In contrast, female $758 \mathrm{~F}$ movements were within a small area moving $109 \mathrm{~m}$ from tagging to tag sloughing, in a tracked time of 39 days, behaviour typical of females. $758 \mathrm{~F}$ was thought to have been captured by a common buzzard (Buteo buteo) after the tag had been shed. These observations reveal the importance of suitable habitat to create safe dispersal corridors for snakes: overzealous management could result in isolating individual snakes and groups (Photo: N. Hand) 


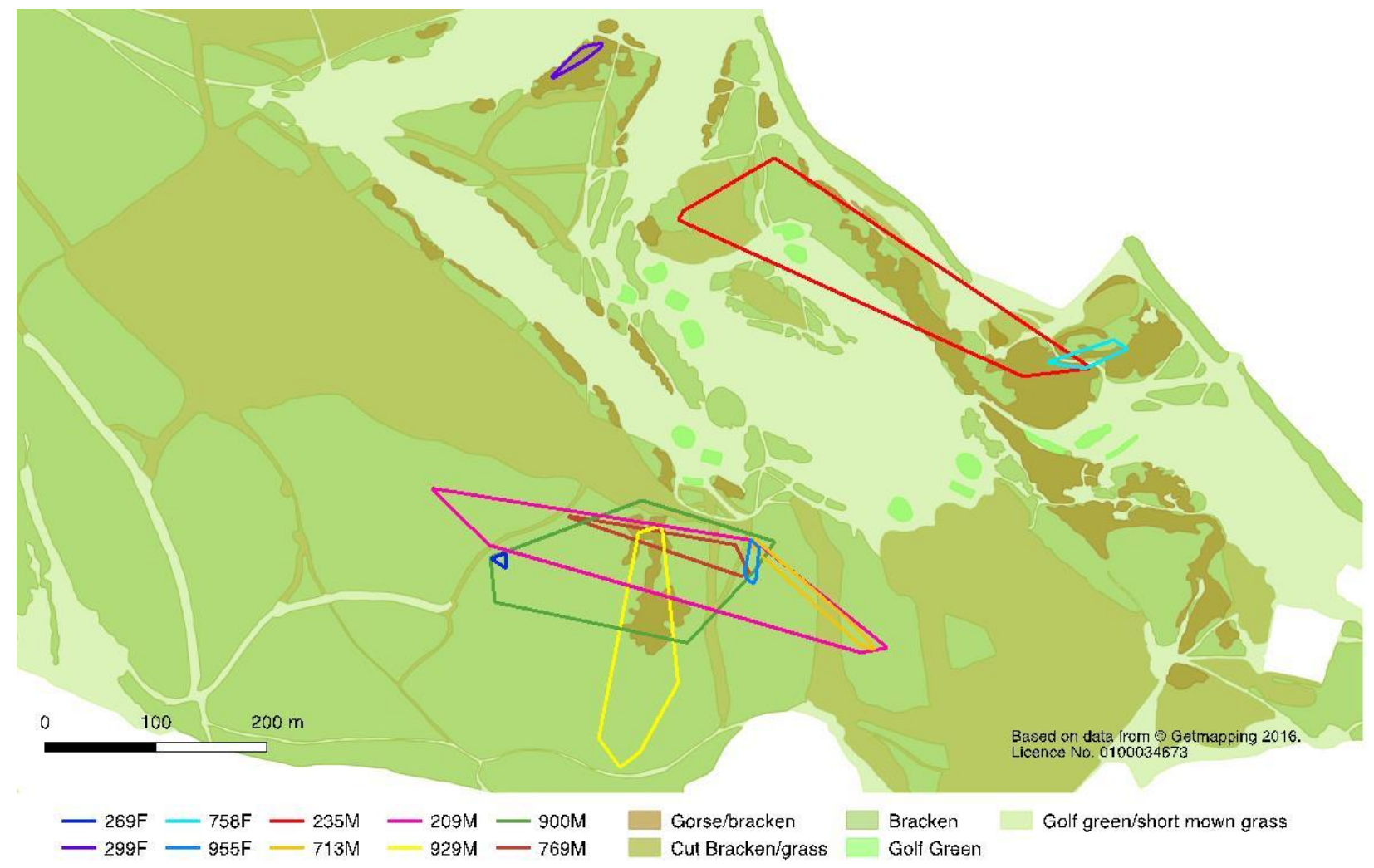

Fig. 5. Home ranges of ten adders (Vipera berus) followed by telemetry tags at a Herefordshire golf course and common, from April to early June 2017. Males moved large distances searching for mates with activity centered on the location of females. Male movements slowed from the end of May and into June, when they exhibited fossorial behaviour as mating declined and feeding commenced. Within the larger group of snakes, male $900 \mathrm{M}$ (length $560 \mathrm{~mm}$ ) was dominant. Originally he was located near female 269F (450 mm), but this female was suspected as non-breeding in 2017 and 900M moved to female $955 \mathrm{~F}$ where three other tagged males were already gathered, as well as two non-tagged males. On arrival the other males moved away, including the previously dominant male 209M (535 mm). Male 235M (500 mm) travelled the furthest distance of $893 \mathrm{~m}$. Male $209 \mathrm{M}$ travelled $743 \mathrm{~m}$ and male $900 \mathrm{M} 642 \mathrm{~m}$. Male 929M (435 mm) descended the slope and did not compete over females, feeding in lower parts of the site. Females remained in small home ranges. The longest female movement of $109 \mathrm{~m}$ was by $758 \mathrm{~F}$ $(570 \mathrm{~mm}$ ); this female was thought to have been taken by a common buzzard (Buteo buteo). The distribution of snakes at this site reflects habitat management, with the larger group of snakes able to move through extensive undisturbed suitable habitat on the common. In contrast snakes on the golf course were within fragmented and disturbed habitat where large areas of bracken were cut providing areas of short grassland for sheep grazing. Such wide expanses of short vegetation result in isolating adders. Thus female $299 \mathrm{~F}(495 \mathrm{~mm}$ ) appeared to be isolated from other snakes. Following these observations habitat management at the site is attempting to address connectivity problems. Similar connectivity issues have been noted on other telemetry sites and likely to be the case at other U.K. adder sites.

Short grassland thus acted as a barrier to adder movement. One male was tracked from a Corsican pine (Pinus nigra) plantation hibernacula, through an old fruit orchard, to an unimproved rough grassland meadow with abundant field vole (Microtus agrestis) burrows and runs. This snake spent much of the remaining tracking time, from May to June, moving within vole runs. Other males were tracked moving from lowland heath, through woodland of mature oak (Quercus spp.) and into woodland glade edge habitat, where a small group of females and juveniles was located. In 2018 a large adult male (length $600 \mathrm{~mm}$ ) moved from a small population of fewer than ten snakes, to a much larger population, travelling through deciduous woodland, ascending a steep $150 \mathrm{~m}$ high sandstone escarpment, and onto lowland heath, a distance of nearly $700 \mathrm{~m}$. It is possible that this male had originated from the larger population, and so this may have been a return visit.
A few snakes and their tags were lost during tracking. There have been two confirmed predations. A female adder from a hillside summit with its tag tracked and retrieved beneath an oak tree in a deciduous coppice $800 \mathrm{~m}$ away from the last recorded location. An active common buzzard (Buteo buteo) nest was noted in the tree above. It was concluded that the snake had been caught on the hillside by a buzzard and fed to its chicks in the nest.

\section{CONCLUSIONS}

\section{Telemetry mapped movements}

From April to June observations suggest that males move further and have greater home ranges than females. Males during this period moved an average distance of $570 \mathrm{~m}$ : these movements are typically males searching for mates. The longest recorded distance from capture to final recorded location was 2,207 m was by a melanistic male. However, not all males roamed widely. In contrast, females remained 
within small areas usually near hibernacula with some remaining beneath a single gorse (Ulex spp.) or bramble (Rubus fruticosus agg.) patch.

Male adders possibly develop familiarity with landscapes learnt through mate searching over successive years, when they roam over wide areas and habitat types, finally returning to the original location areas. These observations have implications for habitat management or land change at adder sites. Furthermore, they suggest that translocation projects, moving snakes to new areas, could be disorientating to some snakes.

Mature deciduous woodlands are not necessarily a barrier to dispersal as snakes can move through them. Thus the recent conservation policy to create and manage woodlands as open wooded pasture may suit adders, particularly when these areas are close to existing populations, or form a corridor between areas of open habitat.

Snake breeding and combat does not necessarily occur in the same areas each year, but is dependent on the location of breeding females.

Adders were observed to cross footpaths, unmade roads and off-road tracks on all sites, sometimes repeatedly crossing the same tracks. Males searching for mates crossed mown tracks up to $30 \mathrm{~m}$ wide, but were never witnessed crossing tarmac roads. At one site, popular with dog walkers, two populations of adders were divided by a tarmac road. Here the snakes moved close to the road edges on both roadsides, but no snakes crossed the road during the tracking period.

Males are fossorial after the breeding period, from April to July, spending much time undercover or underground. This may be important for humidity, foraging, protection from predators, escape from inclement weather and overnight refuge. Snakes were regularly noted with prey bulges when found below vegetation or refuge piles. This observation has important implications for the timing of adder location and capture during surveys or translocation projects. This period of the year will be the least effective for observational survey or capture of snakes, particularly males. Such fossorial activity also has implications for site management. Cutting and scarifying bracken, gorse or rough grassland areas could lead to snake mortalities, compacted soil structure, loss of insulating thatch and damp humus, and a reduction in prey species.

Between May and June snakes move from spring habitats of open heath or hillside slopes to semishaded woodland edges, stands of trees, such as silver birch (Betula pendula) or within thicker gorse blocks. The ambient temperatures during this period of the year remain stable, allowing snakes to frequent such areas.
Snakes were noted regularly within woody brash piles created by habitat management work parties. On one site a number of woody piles had mossed over providing ideal snake cover, along with rodent runs and burrows.

Whilst tracking adders a diverse range of animal species were also found in bracken. These included:

1. Mammals, such as nesting dormice (Muscardinus avellanarius), nests of harvest mice (Micromys minutus), common shrews (Sorex araneus) and pygmy shrews (Sorex minutus). Field vole runs were also found in bracken humus.

2. Amphibians, such as toads (Bufo bufo), great crested newts (Triturus cristatus) and common frogs (Rana temporaria).

3. Birds, such as meadow pipits (Anthus pratensis), roosting short-eared owls (Asio flammeus), common snipes (Gallinago gallinago) and woodcocks (Scolopax rusticola).

4. Butterflies, such as the pearl-bordered fritillary (Boloria euphrosyne).

Implications for habitat management for adders Michael et al. (2014) state that "although habitat management can be beneficial, herpetofaunal diversity may still be restricted by the presence of dispersal barriers. Dispersal barriers are not always as simplistic as the presence of a linear feature such as a road and can be difficult to detect by land managers who are not sufficiently experienced with the ecology of target species." Based on this statement and my telemetry work I suggest the following:

1. Greater awareness is needed of the significance of habitat corridors to protect adder populations. This requires avoiding excessively mowed wide expanses resulting in the isolation of snakes. Banks and bunds running across sites may form important linkage corridors.

2. Snakes can move through areas that may not be considered typical habitats, such as travelling between sites through woodland. Outlying areas may also be used, particularly if there is an abundance of prey.

3. Greater awareness is required of the importance of bracken and rough grassland for snakes. Adders may be present in an area but out of site underground particularly from April to July. This observation has important implications for the timing of adder surveys or translocation projects.

\section{ACKNOWLEDGEMENTS}

Thanks to the National Trust, Forestry Commission, Wildlife Trusts, Malvern Hills Trust, Malvern Hills AONB and Natural England for allowing radio telemetry on sites. Thanks also to Nick Saunders for 
mapping assistance and Sylvia Sheldon and Chris Bradley.

\section{REFERENCE}

Michael, D.R., Wood, J.T., Crane, M., Montague-Drake, R. \& Lindenmayer, D.B. (2014). How effective are agri-environment schemes for protecting and improving herpetofaunal diversity in Australian endangered woodland ecosystems? Journal of Applied Ecology 51, 494-504. 